\title{
The relationship between monocarboxylate transporters 1 and 4 expression in skeletal muscle and endurance performance in athletes
}

\author{
David J. Bentley $\npreceq$ Belle Roels $₫$ Claire Thomas $\mathbb{E}$ \\ Robert Ives $\leftleftarrows$ Jacques Mercier $\leftleftarrows$ Grégoire Millet $\leftleftarrows$ \\ David Cameron-Smith
}

Abstract The purpose of this study was to examine the relationship between skeletal muscle monocarboxylate transporters 1 and 4 (MCT1 and MCT4) expression, skeletal muscle oxidative capacity and endurance performance in trained cyclists. Ten well-trained cyclists (mean $\pm \mathrm{SD}$; age $24.4 \pm 2.8$ years, body mass $73.2 \pm 8.3 \mathrm{~kg}, V \mathrm{O}_{2 \max }$ $58 \pm 7 \mathrm{ml} \mathrm{kg}^{-1} \min ^{-1}$ ) completed three endurance performance tasks [incremental exercise test to exhaustion, 2 and 10 min time trial (TT)]. In addition, a muscle biopsy sample from the vastus lateralis muscle was analysed for

\section{J. Bentley $(\&) \cdot R$. Ives}

Health and Exercise Science, School of Medical Science,

University of New South Wales, The Goodsell Building,

Sydney, NSW 2052, Australia

e-mail: d.bentley@unsw.edu.au

\section{B. Roels}

UPRES EA 3759 “'Multidisciplinary Approach of Doping”, 700 avenue Pic St Loup, 34090 Montpellier, France

B. Roels $\cdot$ C. Thomas $\cdot$ J. Mercier

UFR Médecine, EA701, Université Montpellier 1,

34295 Montpellier, France

\section{Thomas}

STAPS Department, UFR des Sciences Fondamentales et Appliquees, University of Evry Val D'Essonne,

56 Bvd des Coquibus, 91025 Evry, France

\section{J. Mercier}

INSERM, ERI 25, 34295 Montpellier, France

\section{G. Millet}

Institut des sciences du sport et de l'éducation physique,

Université de Lausanne, Lausanne, Switzerland

\section{Cameron-Smith}

School of Nutrition and Exercise Sciences, Deakin University, Burwood, Melbourne, VIC, Australia
MCT1 and MCT4 expression levels together with the activity of citrate synthase (CS) and 3-hydroxyacyl-CoA dehydrogenase (HAD). There was a tendency for $V \mathrm{O}_{2 \max }$ and peak power output obtained in the incremental exercise test to be correlated with MCT1 $(r=-0.71$ to -0.74 ; $P W 0.06)$, but not MCT4. The average power output $\left(P_{\text {average }}\right)$ in the 2 min TT was significantly correlated with MCT4 $(r=-0.74 ; \quad P W 0.05)$ and HAD $(r=-0.92$; $P W 0.01)$. The $P_{\text {average }}$ in the $10 \mathrm{~min}$ TT was only correlated with CS activity ( $r=0.68 ; P W 0.05)$. These results indicate the relationship between MCT1 and MCT4 as well as cycle TT performance may be influenced by the length and intensity of the task.

Keywords Aerobic $\cdot$ Cycling $\cdot$ Power $\cdot$ Regulation $\cdot$ Correlation

Introduction

Skeletal muscle phenotype is fundamentally important in producing prolonged forceful muscle contractions (Larsson and Karlsson 1978). Studies in untrained subjects show the ability of whole muscle to oxidise pyruvate is significantly linked to whole body submaximal physiological parameters like the lactate threshold (LT) in trained and untrained subjects (Ivy et al. 1980; Coyle et al. 1988). Other studies show glucose uptake and lactate kinetics can be influenced by the expression of GLUT4 and monocarboxylate transporter 1 and 4 (MCT1 and MCT4), respectively in skeletal muscle of untrained subjects (Hardin et al. 1995; Messonnier et al. 2007; Thomas et al. 2005). However, the research conducted so far is limited and conflicting in terms of directly examining the relationship between whole body physiological parameters like maximal aerobic power 
$\left(V \mathrm{O}_{2 \max }\right)$ and the $\mathrm{LT}$, endurance performance, i.e. a time trial (TT) and skeletal muscle phenotype in athletes (Bishop et al. 2000; Coyle et al. 1991; Weston et al. 1999). This is largely due to differences in gender, training status, the performance task quantified and the skeletal muscle characteristics determined. The majority of studies in athletes have examined the relationship between muscle fibre type and endurance performance over a variety of distances and exercise modes (Bishop et al. 2000; Coyle et al. 1991; Weston et al. 1999; Farrell et al. 1979; Foster et al. 1978). These studies clearly indicate that the distance of the task may influence the relationship between performance and skeletal muscle phenotype.

One study found no significant relationship between the average power output over $40 \mathrm{~km}$ and the muscle fibre composition and muscle enzyme activity in moderately trained female cyclists (Bishop et al. 2000). However, it was shown that type IIa $(r=-0.60)$ and type IIb $(r=$ -0.63) areas were related to $40-\mathrm{km}$ performance. It was concluded that the smaller fibre area may allow for a greater capillary density and thus a higher rate of lactate removal. Other studies have supported this finding demonstrating a relationship between muscle capillarization and lactate accumulation during incremental exercise in untrained subjects (Sjodin et al. 1981; Tesch et al. 1981). Hence skeletal muscle lactate transport and dissipation could be one mechanism by which endurance performance in athletes could be enhanced in endurance tasks of very high intensity and short duration (Messonnier et al. 2007; Thomas et al. 2005).

The trans-skeletal muscle membrane movement of lactate is facilitated by membrane-bound MCTs (Garcia et al. 1994). The MCTs are a family of proteins that are expressed in a cell-specific pattern in human and animal skeletal muscle (Halestrap and Price 1999). The MCT1 isoform has been shown to be positively correlated with the percentage number of type I fibres in humans (Pilegaard et al. 1999). The expression of MCT1 is also lower in white muscle obtained from rodents (Juel 1996; McCullagh et al. 1996; Wilson et al. 1998). In contrast, MCT4 protein is expressed predominantly in type II muscle fibres (Wilson et al. 1998). There are a number of hypothesis concerning the functional role of MCT1 and MCT4; however, it is possible that lactate flux and subsequent metabolism could be improved during exercise with increased expression of MCT1 (Messonnier et al. 2007; Thomas et al. 2005). Thus, it is possible at a peripheral muscular level, proteins regulating lactate metabolism may exhibit differential influences on fatigue and performance in high-intensity endurance tasks imposing contrasting metabolic demands. However, the relationship between selected performance variables in short or longer TTs or performance in incremental exercise tasks together with MCT1 and MCT4 have not been examined in trained endurance athletes.

Therefore, the purpose of this experiment was to determine the relationship between muscle oxidative capacity, the expression of lactate transport (MCT1 and MCT4 proteins) and endurance performance in trained cyclists. We hypothesised that endurance performance would be related to MCT1 and MCT4 as well as muscle oxidative capacity.

\section{Materials and methods}

Subjects

Ten male cyclists (mean $\pm \mathrm{SD}$; age $24.4 \pm 2.8$ years, body mass $73.2 \pm 8.3 \mathrm{~kg}, V \mathrm{O}_{2 \max } 58 \pm 7 \mathrm{ml} \mathrm{kg}^{-1} \min ^{-1}$ ) volunteered to participate in the study after verbal and documented description of risks and requirements of the study. All the subjects signed an informed consent document and were familiarised with the protocols and equipment used in the incremental testing and endurance performance analysis having completed similar testing using the same equipment. The physical and performance characteristics of the participating subjects are presented in Table 1. The experimental procedures were approved by the institutional ethics committee in accordance with National Health and Medical Research Council guidelines.

\section{Laboratory performance tests}

The subjects completed three different endurance performance tests in the laboratory under standard environmental conditions (temperature $* 20^{\circ} \mathrm{C}$; relative humidity $* 50 \%$ ). The first test comprised a progressive incremental test to exhaustion to determine the maximal oxygen uptake $\left(V \mathrm{O}_{2 \max } ; \mathrm{ml} \mathrm{kg}^{-1} \mathrm{~min}^{-1}\right)$ and peak power output (PPO; $\mathrm{W})$. The test began with $3 \mathrm{~min}$ at an initial power output of $60 \mathrm{~W}$ and than the workload progressively increased by $30 \mathrm{~W}$ every minute until exhaustion (Bentley et al. 2007). Respiratory gas exchange was measured continuously during the test by a $\mathrm{K} 4^{\mathrm{b} 2}$ (Cosmed, Rome, Italy) which has been previously validated (Duffield et al. 2004). Before

Table 1 Mean \pm SD physical and maximal physiological results from the incremental test

\begin{tabular}{lc}
\hline Variable & Mean \pm SD \\
\hline Body mass $(\mathrm{kg})$ & $73.2 \pm 8.3$ \\
$V \mathrm{O}_{2 \max }\left(\mathrm{ml} \mathrm{kg}^{-1} \mathrm{~min}^{-1}\right)$ & $58.5 \pm 7.3$ \\
$V \mathrm{O}_{2 \max }\left(1 \mathrm{~min}^{-1}\right)$ & $4,271 \pm 650$ \\
PPO (W) & $339.0 \pm 48.8$
\end{tabular}


each test, the Cosmed system was calibrated according to manufacturer's recommendations. At the end of the test breath-by-breath data were averaged every $30 \mathrm{~s}$ and $V \mathrm{O}_{2 \max }$ determined as the highest $30 \mathrm{~s} V \mathrm{O}_{2}$ average. The PPO was defined as the highest mechanical power maintained during $1 \mathrm{~min}$ of the test (Bentley et al. 2007).

The second and third performance tests comprised a 2- and 10-min TT, respectively. The TT required the subjects to cycle at the highest power output for the 2 or 10 min duration. The average power output $\left(P_{\text {average }}, \mathrm{W}\right)$ was also determined during the entire TT and expressed in absolute terms (Watts) (W). In addition, lactate concentration $\left(\mathrm{La}_{\max } ; \mathrm{mmol} \mathrm{l}^{-1}\right)$ was measured in mixed arteriovenous 'finger tip' blood samples immediately after completion of each trial using a portable analyser (Lactate Pro, Arkray Inc., Kyoto, Japan) as previously described and validated (Pyne et al. 2000).

All the tests were performed on the subject's bicycle equipped with a 'SRM ${ }^{\circledR}$ road professional' powermeter (Schoberer Rad Messtechnik, Jülich, Walldorf, Germany). The dimensions of the ergometer were kept identical for all the tests. Power output and the pedaling cadence were recorded with an acquisition frequency of $1 \mathrm{~s}$. The calibration of the SRM crank system was performed as previously recommended included warm up and zero offset of the acquisition unit (Gardner et al. 2004). The reliability and validity of the SRM crank has also been previously described (Bertucci et al. 2005).

\section{Skeletal muscle biopsy}

Muscle samples were obtained from the vastus lateralis using the percutaneous needle biopsy technique after administration of local anaesthesia (xylocaine). The biopsies were taken by the same researcher from the same site. The muscle samples were immediately frozen in liquid nitrogen and stored at $-80^{\circ} \mathrm{C}$ until further analysis.

\section{Sample preparation for western blotting}

Proteins were isolated from each muscle sample by a method previously described (McCullagh et al. 1996). Muscle protein concentration was determined in duplicate by bicinchoninic acid assay (Pierce, Interchim, Montluçon, France) with BSA as a standard. Affinity polyclonal antibodies directed against the carboxy terminus of human MCT1 and MCT4 were produced with the synthetic peptide C-Ahx-KDTEGGPKEEESPV-OH for MCT1 and C-AHX-GEVVHTPETSV-OH for MCT4. The peptides were linked with their cysteine residue at KLH EDC-activated carrier protein according to a protocol recommended by the manufacturer (Pierce, Interchim, Montluçon, France) and the resulting solutions injected as specific antigens for immunisation of New Zealand white rabbits. Western blotting were probed with these antibodies and Chemicon International antibodies (Temecula, CA, USA; rabbit anti-MCT1: AB3538P and rabbit anti-MCT4: AB3316P). Polyclonal antibodies yielded a single band on a western blot that corresponded to $43 \mathrm{kD}$, consistent with the molecular mass reported earlier (McCullagh et al. 1996). Antibody specificities were confirmed in preliminary experiments in which the peptides blocked the detection of MCT1 and MCT4. Samples of muscle homogenates $(12 \mathrm{lg}$ protein) and prestained molecular mass markers (BioRad), were separated on $10 \%$ Bis-Tris-acrylamide gels ( $200 \mathrm{~V}$ for $* 60 \mathrm{~min}$ ) with the Novex system (Invitrogen, Groningen, The Netherlands). A large sample of a human biopsy was prepared. At each time, this sample was added and served as control for all gels. Proteins were then transferred from the gels to polyvinylidene difluoride membranes ( $30 \mathrm{~V}, 180 \mathrm{~min}$ ), and the membranes were incubated on a shaker overnight at $4^{\circ} \mathrm{C}$ temperature in buffer $\mathrm{D}\left[20 \mathrm{mmol} \mathrm{l}^{-1}\right.$ Tris base, $137 \mathrm{mmol} \mathrm{l}^{-1} \mathrm{NaCl}, 0.1 \mathrm{~mol} \mathrm{l}^{-1} \mathrm{HCl}$, adjusted to $\mathrm{pH}$ 7.5, $0.1 \%(\mathrm{vol} / \mathrm{vol})$ Tween 20 , and 5\% (wt/vol) nonfat dried milk]. The membranes were then incubated with diluted carboxy-terminal of either MCT1 antibody $(1: 90,000)$ or MCT4 $(1: 90,000)$ in buffer D for $2 \mathrm{~h}$ at room temperature, followed by four washes (4 $95 \mathrm{~min}$ washes) in buffer E, i.e. buffer D without dried milk and then incubated for $50 \mathrm{~min}$ with goat anti-rabbit immunoglobulin G horse-radish peroxidase-conjugated secondary antibody $(1: 10,000, \mathrm{BI} 2407$, BioSys, Compiègne, France) in buffer E. Membranes were washed as previously described and MCT1 or MCT4 expression was detected by ECL (Biomax MR films, Kodak, RueilMalmaison, France). Films were developed and fixed using a Hyperprocessor (RNP 1700, Amersham, Les Ulis, France). MCT1 and MCT4 protein band densities determined by scanning the blots on a scanner (AGFA Duo Scan T1200, New York, USA) and Scion Image software (Scion Corp, Frederick, MD, USA). Results were expressed in arbitrary optical density units (AU).

\section{Muscle enzyme activity}

Muscle homogenates were initially prepared in a solubilizing buffer containing sucrose $210 \mathrm{nM}$, EGTA $2 \mathrm{nM}$, $\mathrm{NaCl} 40 \mathrm{mM}$, HEPES $30 \mathrm{mM}$, EDTA 5mM, and phenylmethylsulfonyl fluoride $2 \mathrm{mM}$ ( $\mathrm{pH} 7.4$ ), and stored at $-80^{\circ} \mathrm{C}$. Citrate synthase (CS) and HAD activity was subsequently determined by spectrophotometry with changes in absorbance recorded over $3 \mathrm{~min}$ at $412 \mathrm{~nm}$ at $25^{\circ} \mathrm{C}$ (Srere 1969). 
Statistical analysis

All values are reported as mean \pm SD. Pearson's product moment correlations were used to examine the relationship between skeletal muscle characteristics and endurance performance. Statistical significance was accepted at $P W 0.05$.

Results

Performance in the time trial and incremental test

The maximal physiological results obtained from the incremental test and submaximal results from both the TT tasks are shown in Tables 1 and 2. The relationship between the average power output in the 2 min TT was significantly but weakly correlated with $V_{2} \mathrm{O}_{2 \max }$ $\left(\mathrm{ml} \mathrm{kg}{ }^{-1} \mathrm{~min}^{-1}\right) \quad(r=0.64 ; P W 0.05)$ and PPO (W) ( $r=0.73 ; P W 0.02$ ). The average power output in the 10 min TT was not significantly correlated with $V \mathrm{O}_{2 \max }$ $\left(\mathrm{ml} \mathrm{kg}{ }^{-1} \min ^{-1}\right)(r=0.60)$ but was highly correlated to PPO (W) $(r=0.91 ; P W 0.0001)$. There was a significant relationship between the average power output obtained in the 2 and 10-min TT ( $r=0.81 ; P W 0.01)$.

\section{Skeletal muscle characteristics}

The mean \pm SD protein content for MCT1 and MCT4 as well CS and HAD activity are shown in Table 3. MCT1 was not correlated with MCT4 protein levels $(r=0.55)$. CS activity was also not significantly correlated with MCT1 $(r=-0.65)$ and MCT4 $(r=-0.41)$. HAD activity was also not significantly correlated with MCT1 $(r=$ -0.01) and MCT4 ( $r=0.59)$ protein content.

Skeletal muscle and endurance performance

There was a tendency for $V \mathrm{O}_{2 \max }\left(1 \mathrm{~min}^{-1}\right)(r=-0.71$; $P=0.08)$ and PPO (W) $(r=-0.74 ; P=0.06)$ to be inversely associated with MCT1. Aside from this result, no

Table 2 Mean \pm SD submaximal physiological responses obtained from the 2 and 10 min time trials

\begin{tabular}{lc}
\hline Variable & Mean \pm SD \\
\hline 10 min time trial & \\
$P_{\text {average }}(\mathrm{W})$ & $255.3 \pm 41.0$ \\
$\mathrm{La}(\mathrm{mM})$ & $12.7 \pm 5.4$ \\
2 min time trial & \\
$P_{\text {average }}(\mathrm{W})$ & $345.5 \pm 54.3$ \\
$\mathrm{La}(\mathrm{mM})$ & $14.8 \pm 3.4$ \\
\hline
\end{tabular}

Table 3 Mean \pm SD skeletal muscle protein content and enzyme activity in muscle samples of participating subjects

\begin{tabular}{lr}
\hline Variables & \multicolumn{1}{c}{ Mean \pm SD } \\
\hline MCT1 & $1.71 \pm 0.65$ \\
MCT4 & $2.49 \pm 0.49$ \\
CS & $20.72 \pm 5.87$ \\
HAD & $1.10 \pm 0.89$ \\
\hline
\end{tabular}

significant correlation was found between $V \mathrm{O}_{2 \max }$ (expressed in absolute terms or relative to body mass) or PPO and any of the skeletal muscle characteristics. The average power output (W) during the 2-min TT was significantly correlated with MCT4 protein levels $(r=-0.74$; $P W 0.05)$. Hence, the higher the expression of MCT4 the lower the performance level. In addition, $2 \mathrm{~min}$ TT performance was highly correlated to HAD activity $(r=$ -0.92; $P W 0.0001)$ and the ratio between CS:HAD ( $r=0.72 ; P W 0.05)$. The average power output during the 10-min TT was significantly correlated with CS activity ( $r=0.68 ; P W 0.05)$. There was no significant correlation between 10-min TT performance and HAD enzyme activity $(r=-0.58)$. There was also no significant correlation between 10-min TT and MCT1 or MCT4 expression levels. The La in the 2-min TT was significantly correlated with CS activity $(r=0.71 ; P W 0.05)$. Aside from this result there were no significant correlations between any of the skeletal muscle characteristics and $\mathrm{La}$ at the completion of the 2 or 10 -min TT (Table 4).

\section{Discussion}

Skeletal muscle is fundamentally important in producing muscle contractions of varied force, velocity and duration. The purpose of the present study was to examine the relationship between endurance performance and the expression of lactate transport proteins (MCT1 and MCT4). In this regard, we hypothesised that performance during the TTs (of short duration) would be correlated with the expression of MCT1, MCT4 and skeletal muscle oxidative capacity. The important findings of this study were that PPO and $V \mathrm{O}_{2 \max }$ were correlated to performance (average power output) in the 2 and 10-min TT. In addition, MCT4 as well as the activity of HAD were inversely correlated with performance in 2-min TT.

In this study, we found that there was a tendency for MCT1 protein content to be inversely correlated with $V \mathrm{O}_{2 \max }$ and PPO obtained in the incremental test as well as the average power output during the 10-min TT. We also found MCT4 was inversely correlated to performance in the 2-min TT. Hence, these data indicate that in trained 
Table 4 Correlation matrix demonstrating the relationship $(r)$ between the results of the performance testing and skeletal muscle analysis

\begin{tabular}{|c|c|c|c|c|c|c|c|c|}
\hline & 1 & 2 & 3 & 4 & 5 & 6 & 7 & 8 \\
\hline 1. $V \mathrm{O}_{2 \max }\left(1 \mathrm{~min}^{-1}\right)$ & - & $0.72 *$ & $0.64 *$ & 0.61 & -0.28 & -0.43 & 0.24 & -0.09 \\
\hline 2. PPO (W) & & - & $0.73^{*}$ & $0.92 * *$ & -0.74 & -0.41 & 0.47 & -0.34 \\
\hline 3. $P_{\text {average }}(2 \min \mathrm{TT}$ & & & - & $0.81 * *$ & -0.23 & $-0.74 *$ & 0.59 & $-0.92 * *$ \\
\hline 4. $P_{\text {average }}(10 \mathrm{~min} \mathrm{TT})$ & & & & - & -0.72 & -0.46 & $0.68 *$ & -0.58 \\
\hline 5. MCT 1 & & & & & - & 0.55 & -0.65 & -0.01 \\
\hline 6. MCT 4 & & & & & & - & -0.41 & 0.59 \\
\hline 7. $\mathrm{CS}$ & & & & & & & - & -0.44 \\
\hline 8. HAD & & & & & & & & - \\
\hline
\end{tabular}

*PW $0.05, * * P W 0.01$

athletes a higher expression level of MCT1 and MCT4 does not positively influence endurance performance and indeed may well be detrimental to endurance performance of this type. Another recent investigation in untrained subjects have demonstrated an opposing influence with both MCT1 and MCT4 significantly correlated with time to fatigue and post-exercise blood lactate concentration following exercise at $120 \% \mathrm{VO}_{2 \max }$ (Messonnier et al. 2007). In another study, Thomas et al. (2005) have shown that MCT1 and MCT4 are correlated to lactate dissipation following supramaximal exercise. Apart from this, the authors of the former study have proposed that the better trained subjects relied less on lactate transport and more on buffering capacity, muscle capillarization and peripheral blood flow. This could explain the contrasting results of these studies and the present investigation. At the same time, other training studies both performed in athletes have shown that MCT1 and MCT4 remain unchanged after a period of intensified training (Clark et al. 2004; Bishop et al. 2008). Also, other studies have shown that the expression of MCT1 and MCT4 acutely decreased following a single bout of high-intensity exercise (Bishop et al. 2007). Furthermore, Bishop et al. (2000) have concluded that capillary density might be more important for lactate dissipation and partly associated with performance in a 40-km TT in female cyclists. Combining the results of this study and the data of others, it would appear that MCT1 and MCT4 are not influential for endurance performance of short duration/high intensity and other factors such as peripheral blood flow, capillarization and buffering capacity may be more important.

In this study, we found a significant correlation between CS activity and performance during the $10 \mathrm{~min}$ TT. A number of previous studies have examined which muscle phenotype characteristics influence endurance performance in athletes (Bishop et al. 2000; Weston et al. 1999; Horowitz et al. 1994; Coyle et al. 1988, 1991). In these studies, the percentage type I fibres in whole muscle seems to be correlated to endurance performance over a longer duration, i.e. $40 \mathrm{~km}$ or with indirect parameters of endurance performance such as whole body metabolic efficiency (Coyle et al. 1988, 1991). Coyle et al. (1991) also found that the average power output during a $40-\mathrm{km}$ TT was highly correlated to percentage type I fibres $\left(r^{2}=0.91\right)$ and muscle myoglobin content $\left(r^{2}=0.91\right)$ in elite athletes with a $V \mathrm{O}_{2 \max }$ exceeding $70 \mathrm{ml} \mathrm{kg} \mathrm{km}^{-1} \mathrm{~min}^{-1}$. However, a 'national-level group' of cyclists was inferior in regards to $40-\mathrm{km}$ TT performance as well as the percentage type I composition and myoglobin content indicating that these characteristics may be important in determining endurance performance over a duration of *60 min. The mechanisms for this are largely unknown; however, other studies have shown that exercise efficiency is highly correlated ( $r=0.75-0.85)$ to percentage type I fibres in subjects with an elevated $V \mathrm{O}_{2 \max }$ (Coyle et al. 1991, 1992). These data suggest that endurance athletes who possess a greater number of slow twitch fibres have greater efficiency which may result in heightened performance in events around 60-min duration. We did not measure muscle fibre type, either by standard histochemistry or by electrophoresis (myosin heavy chain isoform I); however, in skeletal muscle of untrained individuals the percentage type $\mathrm{I}$ is typically correlated the activity of CS (Borges and EssénGustavsson 1989). In another investigation CS activity was shown to be significantly correlated $(r=0.70)$ to performance (time to fatigue) during a running test to exhaustion in elite runners (Weston et al. 1999). These authors concluded that a higher muscle oxidative capacity was associated with reduced lactate production and improved fatigue resistance. It is interesting to note that the correlation between CS activity and performance outcome of this study and that of Weston et al. (1999) was similar together with the duration of the performance task. Hence, it is possible that while there is some variability in the skeletal muscle oxidative capacity of athletes, performance is improved with a greater CS activity. By contrast, one study in competitive cyclists 
showed that CS activity does not change with short-term intensified training and is not related to performancerelated improvements in $40 \mathrm{~km}$ with this training (Weston et al. 1997). In this regard, other pioneering researchers have suggested that $\mathrm{CS}$ activity and $V \mathrm{O}_{2 \max }$ are related in untrained subjects but this relationship may not be evident in trained athletes (Holloszy and Coyle 1984). The data from this study and previous work demonstrates that there may be a ceiling effect where no further improvements in CS occur despite a training-induced improvement in performance. However, it is also plausible that the relationship between muscle oxidative phenotype and performance is influenced by the performance task completed. As demonstrated in this study CS activity was correlated with 10-min TT performance but not with 2 min performance. The demands of these activities appear to be metabolically contrasting and it possible that other muscular and indeed neurological characteristics, i.e. motor unit recruitment maybe more important for endurance performance over a short duration (Chapman et al. 2007; Coyle et al. 1991).

In conclusion, this study demonstrates that MCT1 and MCT4 are not related to endurance performance in a TT or incremental exercise test and may even be detrimental to performance. Furthermore, skeletal muscle oxidative capacity is not related to a cycle TT of 2 min duration and only a weak correlation with performance of $10 \mathrm{~min}$ duration. Hence, it appears that other factors aside from the muscle oxidative phenotype are associated with cycling performance in athletes.

\section{Perspective}

This study has shown that in trained athletes, the influence of the expression level of MCT1 and MCT4 may not be as pronounced in these subjects compared with the existing literature examining sedentary subjects. This adds to the existing literature examining the physiological role of MCTs in human subjects. Importantly, this study indicates that there may well be an adverse effect of increased expression levels of MCT4 on cycling performance of very short duration and at near maximal intensity. It may well be that in athletes performing intensive exercise tasks other factors dictate performance outcome. The results of this study also suggest that the relationship between whole body physiological variables and skeletal muscle may not necessarily be strong and this is in contrast with those studies conducted in untrained individuals. Further studies are required to examine which genes are upregulated in athletes in response to training as well as the physiological significance for athletic performance.
Acknowledgments This study was financially supported by grants from the International Olympic Committee, the French Ministry of Sport and faculty (Medicine) research grants University of NSW, Sydney, Australia.

\section{References}

Bentley DJ, Newell J, Bishop D (2007) Incremental exercise test design and analysis: implications for performance diagnostics in endurance athletes. Sports Med 37(7):575-586. doi:10.2165/ 00007256-200737070-00002

Bertucci W, Duc S, Villerius V, Pernin JN, Grappe F (2005) Validity and reliability of the PowerTap mobile cycling powermeter when compared with the SRM device. Int J Sports Med 26(10): 868-873. doi:10.1055/s-2005-837463

Bishop D, Jenkins DG, McEniery M, Carey MF (2000) Relationship between plasma lactate parameters and muscle characteristics in female cyclists. Med Sci Sports Exerc 32(6):1088-1093. doi: 10.1097/00005768-200006000-00008

Bishop D, Edge J, Thomas C, Mercier J (2007) High-intensity exercise acutely decreases the membrane content of MCT1 and MCT4 and buffer capacity in human skeletal muscle. J Appl Physiol 102(2):616-621. doi:10.1152/japplphysiol.00590.2006

Bishop DJ, Edge J, Thomas C, Mercier J (2008) Effects of highintensity training on muscle lactate transporters and postexercise recovery of muscle lactate and hydrogen ions in women. Am J Physiol Regul Integr Comp Physiol [Epub ahead of print]

Borges O, Essén-Gustavsson B (1989) Enzyme activities in type I and II muscle fibres of human skeletal muscle in relation to age and torque development. Acta Physiol Scand 136(1):29-36. doi: 10.1111/j.1748-1716.1989.tb08626.x

Chapman AR, Vicenzino B, Blanch P, Hodges PW (2007) Leg muscle recruitment during cycling is less developed in triathletes than cyclists despite matched cycling training loads. Exp Brain Res 181(3):503-518. doi:10.1007/s00221-007-0949-5

Clark SA, Aughey RJ, Gore CJ, Hahn AG, Townsend NE, Kinsman TA, Chow CM, McKenna MJ, Hawley JA (2004) Effects of live high, train low hypoxic exposure on lactate metabolism in trained humans. J Appl Physiol 96(2):517-525. doi:10.1152/ japplphysiol.00799.2003

Coyle EF, Coggan AR, Hopper MK, Walters TJ (1988) Determinants of endurance in well-trained cyclists. J Appl Physiol 64(6):26222630

Coyle EF, Feltner ME, Kautz SA, Hamilton MT, Montain SJ, Baylor AM, Abraham LD, Petrek GW (1991) Physiological and biomechanical factors associated with elite endurance cycling performance. Med Sci Sports Exerc 23(1):93-107. doi: 10.1249/00005768-199101000-00015

Coyle EF, Sidossis LS, Horowitz JF, Beltz JD (1992) Cycling efficiency is related to the percentage of type I muscle fibers. Med Sci Sports Exerc 24(7):782-788. doi:10.1249/00005768199207000-00008

Duffield R, Dawson B, Pinnington HC, Wong P (2004) Accuracy and reliability of a Cosmed K4b2 portable gas analysis system. J Sci Med Sport 7(1):11-22. doi:10.1016/S1440-2440(04) 80039-2

Farrell PA, Wilmore JH, Coyle EF, Billing JE, Costill DL (1979) Plasma lactate accumulation and distance running performance. Med Sci Sports 11(4):338-344

Foster C, Costill DL, Daniels JT, Fink WJ (1978) Skeletal muscle enzyme activity, fibre composition and $\mathrm{VO}_{2 \max }$ in relation to distance running performance. Eur J Appl Physiol 39:73-80. doi: 10.1007/BF00421711 
Garcia CK, Goldstein JL, Pathak RK, Anderson RG, Brown MS (1994) Molecular characterization of a membrane transporter for lactate, pyruvate, and other monocarboxylates: implications for the Cori cycle. Cell 76(5):865-873

Gardner AS, Stephens S, Martin DT, Lawton E, Lee H, Jenkins D (2004) Accuracy of SRM and power tap power monitoring systems for bicycling. Med Sci Sports Exerc 36(7):1252-1258. doi:10.1249/01.MSS.0000132380.21785.03

Halestrap AP, Price NT (1999) The proton-linked monocarboxylate transporter (MCT) family: structure, function and regulation. Biochem J 343(Pt 2):281-299. doi:10.1042/0264-6021:3430281

Hardin DS, Azzarelli B, Edwards J, Wigglesworth J, Maianu L, Brechtel G, Johnson A, Baron A, Garvey WT (1995) Mechanisms of enhanced insulin sensitivity in endurance-trained athletes: effects on blood flow and differential expression of GLUT 4 in skeletal muscles. J Clin Endocrinol Metab 80(8):2437-2446. doi:10.1210/jc.80.8.2437

Holloszy JO, Coyle EF (1984) Adaptations of skeletal muscle to endurance exercise and their metabolic consequences. J Appl Physiol 56(4):831-838

Horowitz JF, Sidossis LS, Coyle EF (1994) High efficiency of type I muscle fibers improves performance. Int $\mathbf{J}$ Sports Med 15(3):152-157. doi:10.1055/s-2007-1021038

Ivy JL, Withers RT, Van Handel PJ, Elger DH, Costill DL (1980) Muscle respiratory capacity and fiber type as determinants of the lactate threshold. J Appl Physiol 48(3):523-527

Juel C (1996) Lactate/proton co-transport in skeletal muscle: regulation and importance for $\mathrm{pH}$ homeostasis. Acta Physiol Scand 156(3):369-374. doi:10.1046/j.1365-201X.1996.206000.x

Larsson L, Karlsson J (1978) Isometric and dynamic endurance as a function of age and skeletal muscle characteristics. Acta Physiol Scand 104(2):129-136. doi:10.1111/j.1748-1716.1978. tb06259.x

Messonnier L, Kristensen M, Juel C, Denis C (2007) Importance of pH regulation and lactate/ $\mathrm{H}$ ? transport capacity for work production during supramaximal exercise in humans. J Appl Physiol 102(5):1936-1944. doi:10.1152/japplphysiol.00691.2006
McCullagh KJA, Poole RC, Halestrap AP, O'Brien M, Bonen A (1996) Role of the lactate transporter (MCT1) in skeletal muscles. Am J Physiol 271:E143-E150

Pilegaard H, Terzis G, Halestrap A, Juel C (1999) Distribution of lactate/H? transporter isoforms MCT1 and MCT4 in human skeletal muscle. Am J Physiol 276:E843-E848

Pyne DB, Boston T, Martin DT, Logan A (2000) Evaluation of the Lactate Pro blood lactate analyser. Eur J Appl Physiol 82(1-2):112-116. doi:10.1007/s004210050659

Sjodin B, Jacobs I, Karlsson J (1981) Onset of blood lactate accumulation and enzyme activities in $\mathrm{m}$. vastus lateralis in man. Int J Sports Med 2:166-170. doi:10.1055/s-2008-1034605

Srere P (1969) Citrate synthase. Methods Enzymol 13:3-5. doi: 10.1016/0076-6879(69)13005-0

Tesch PA, Sharp DS, Daniels WL (1981) Influence of fibre type composition and capillary density on onset of blood lactate accumulation. Int J Sports Med 2:252-255. doi:10.1055/ s2008-1034619

Thomas C, Perrey S, Lambert K, Hugon G, Mornet D, Mercier J (2005) Monocarboxylate transporters, blood lactate removal after supramaximal exercise, and fatigue indexes in humans. J Appl Physiol 98(3):804-809. doi:10.1152/japplphysiol.01057. 2004

Weston AR, Myburgh KH, Lindsay FH, Dennis SC, Noakes TD, Hawley JA (1997) Skeletal muscle buffering capacity and endurance performance after high-intensity interval training by well-trained cyclists. Eur J Appl Physiol 75:7-13. doi:10.1007/ s004210050119

Weston AR, Karamizrak O, Smith A, Noakes TD, Myburgh KH (1999) African runners exhibit greater fatigue resistance, lower lactate accumulation, and higher oxidative enzyme activity. J Appl Physiol 86(3):915-923

Wilson MC, Jackson VN, Heddle C, Price NT, Pilegaard H, Juel C, Bonen A, Montgomery I, Hutter OF, Halestrap AP (1998) Lactic acid efflux from white skeletal muscle is catalyzed by the monocarboxylate transporter isoform MCT3. J Biol Chem 273(26):15920-15926 